\section{Commentary: "Inside the heart" reconstruction for dextrocardia and systemic venous abnormality at transplantation}

\author{
Subhadra Shashidharan, MBBS
}

Pediatric heart transplant has become the established treatment for end-stage heart failure since the first transplant in 1967. In 2016, the International Society for Heart and Lung Transplantation reported nearly 14,000 pediatric heart transplants have been performed. Transplantation has steadily increased over the past 2 decades, with more than 700 transplants done in $2016 .{ }^{1}$ In total, $40 \%$ of the pediatric heart transplants in North America are performed in patients with congenital heart disease. With improvements in surgical technique, organ procurement and preservation, and immunosuppression, outcomes of heart transplants in pediatric patients have improved over time. Congenital heart disease still presents anatomical challenges. Specifically, dextrocardia-heterotaxy with systemic venous abnormalities makes reconstructions complex. Various case reports with unique techniques have been described.

Reports in literature describe biatrial anastomosis with extracardiac conduits for systemic venous reconstruction, ${ }^{2}$ keeping levocardia; bicaval anastomosis, keeping dextrocardia $^{3}$; and keeping levocardia by opening left pleural space in addition to resecting lung. ${ }^{4}$ Nakamura and colleagues $^{5}$ have presented another technical option for reconstruction and transplantation in infants and young children with heterotaxy dextrocardia. Whereas other techniques are reconstructions using extra cardiac baffles, conduits, and positioning of heart in pericardium, Nakamura

\footnotetext{
From the Department of Surgery, Children's Healthcare of Atlanta, Emory School of Medicine, Atlanta, Ga.

Disclosures: The author reported no conflicts of interest.

The Journal policy requires editors and reviewers to disclose conflicts of interest and to decline handling or reviewing manuscripts for which they may have a conflict of interest. The editors and reviewers of this article have no conflicts of interest.

Received for publication May 27, 2021; revisions received May 27, 2021; accepted for publication June 1, 2021; available ahead of print June 5, 2021.

Address for reprints: Subhadra Shashidharan, MBBS, 1405 Clifton Rd NE, Atlanta, GA (E-mail: Subhadra.shashidharan@emory.edu).

JTCVS Techniques 2021;8:194-5

2666-2507

Copyright (C) 2021 The Author(s). Published by Elsevier Inc. on behalf of The American Association for Thoracic Surgery. This is an open access article under the CC BY-NC-ND license (http://creativecommons.org/licenses/by-nc-nd/4.0/).

https://doi.org/10.1016/j.xjtc.2021.06.003
}

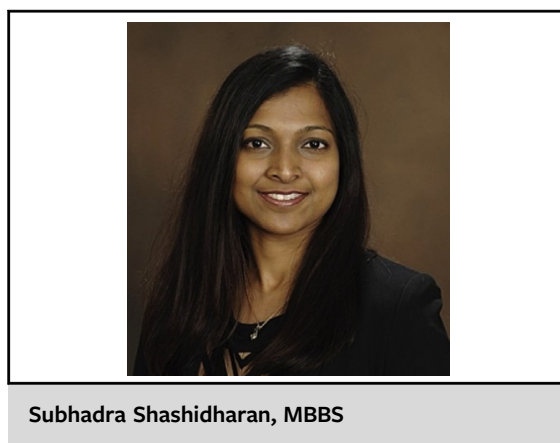

CENTRAL MESSAGE

Cardiac transplantation in pediatric patients with dextrocardia-

heterotaxy can be challenging.

Biatrial anastomosis with intra-

cardiac atrial baffle can be useful

technique for successful implant.

and colleagues provide an intracardiac baffle using atrial switch, aiding the venous reconstruction. The adaptation was particularly important, given the interrupted inferior vena cava with hemiazygous continuation into the left superior vena cava making it short. Atrial switch in the current era has good midterm outcomes with respect to systemic and pulmonary venous obstruction. ${ }^{6}$ The potential benefit of using this technique in preventing venous baffle obstruction mid- to long-term compared with extracardiac conduits, although theoretical, is food for thought.

Due to the rarity of the condition, determining a better technique and long-term outcomes in limited. Since most of the case reports describing extracardiac conduits are in older pediatric patients, atrial switch may be a beneficial technique in younger patients, especially infants. The authors' efforts at thinking of the technique and successful execution are applaudable, despite the unfortunate outcome. The autopsy result showing patent baffles at 4 months is encouraging for greater implementation of the technique.

Dextrocardia-heterotaxy can no longer be considered a contraindication to heart transplant. Successful implants can be performed by using "outside the heart" or "inside the heart" baffles. Congenital transplant surgeons' armamentarium should have all these techniques.

\section{References}

1. Rossano JW, Cherikh WS, Chambers DC, Goldfarb S, Hayes D Jr, Khush KK, et al. The International Thoracic Organ Transplant Registry of the International Society for Heart and Lung Transplantation: twenty-first pediatric heart transplantation report-2018. J Heart Lung Transplant. 2018;37:1184-95. 
2. Doty DB, Renlund DG, Caputo GR, Burton NA, Jones KW. Cardiac transplantation in situs inversus. J Thorac Cardiovasc Surg. 1990;99:493-9.

3. Deuse T, Reitz BA. Heart transplantation in situs inversus totalis. J Thorac Cardiovasc Surg. 2010;139:501-3.

4. Parry AJ, O'Fiesh J, Wallwork J, Large SR. Heart-lung transplantation in situs inversus and chest wall deformity. Ann Thorac Surg. 1994;58:1174-6.
5. Nakamura Y, Ayoubi A, Ashwath R, Exil V, Ricci M. An atrial switch procedure for heart transplantation in an infant with heterotaxy-dextrocardia. J Thorac Cardiovasc Surg Tech. 2021;8:189-91.

6. Ferro G, Murthy R, Forbess J, Sebastian VA, Guleserian KJ, Forbess JM. singlecenter experience with the Senning procedure in the current era. Semin Thorac Cardiovasc Surg. 2016;28:514-20. 